\title{
Extractive Metallurgy and National Policy
}

\author{
Fathi Habashi \\ Department of Mining, Metallurgical, and Materials Engineering, Laval University, Quebec City, Canada \\ Email: Fathi.Habashi@arul.ulaval.ca
}

Received December 13, 2012; revised January 15, 2013; accepted January 24, 2013

Copyright (c) 2013 Fathi Habashi. This is an open access article distributed under the Creative Commons Attribution License, which permits unrestricted use, distribution, and reproduction in any medium, provided the original work is properly cited.

\begin{abstract}
Hydrometallurgical technology offers a unique possibility for developing countries to exploit their mineral resources locally instead of shipping them as concentrates. Production plants may start on a small scale with small capital investment then increase productivity later when the economy permits without financial penalty. This is in contract to smelting operations which necessitates large scale production from the start with high capital investment that may not be available locally.
\end{abstract}

Keywords: Autoclaves; Flash Tanks; Piston Pumps; Smelting; Sulfuric Acid Production; Environmental Problems

\section{Introduction}

Should a country export its mineral wealth in form of concentrates or should it locally treat its ores to produce metals as final products? In the past centuries pyrometallurgy was the only route to extract metals from ores and this required a large capital investment many countries could not afford to raise. This situation encouraged marketing of concentrates. Today, metallurgists have the option to use the hydrometallurgical route to process ores and concentrates at a reasonable capital investment. This opened the way to the possibility of processing ores locally. When need arises to increase production new units can be added economically. This is not possible with pyrometallurgical processes because one large furnace is more economical than a number of small furnaces with the same capacity due to heat radiation losses. However, another factor must also be considered in processing the ores locally: the availability of local experienced manpower. Hence, it is necessary to invest in metallurgical education and research. This is essential to ensure the availability of local engineers who are capable of designing, building, and operating metallurgical plants.

\section{Mineral Wealth and Technology}

Extracting metals from ores or the production of Industrial minerals requires a number of operations: some mechanical, physical, and physicochemical known as mineral beneficiation and some chemical known as extractive metallurgy (Figure 1). The chemical processes can be divided for convenience as pyro-, hydro-, and electrometallurgy. Pyrometallurgy is the most ancient technology, while hydro- and electrometallurgy are more recent. No wonder then that, in some cases, these new technologies are displacing the older ones gradually, either because of improved efficiency and better economics or to comply with environmental regulations [1-3].

Hydrometallurgy is the technology of extracting metals from ores by aqueous methods, pyrometallurgy by dry thermal methods, and electrometallurgy by electrolytic methods. In general, hydrometallurgy involves two distinct steps (Figure 2):

- Selective dissolution of the metal values from an orea process known as leaching.

- Selective recovery of the metal values from the solution, an operation that involves a precipitation method.

Sometimes a purification/concentration operation is conducted prior to precipitation. These processes are aimed at obtaining a pure and a concentrated solution from which the metal values can be precipitated effectively.

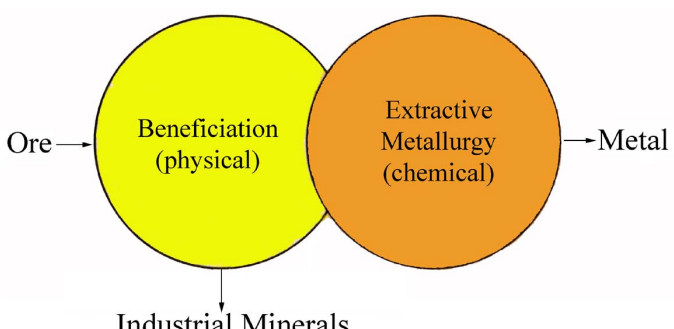

Industrial Minerals

Figure 1. Extracting metals from ores. 


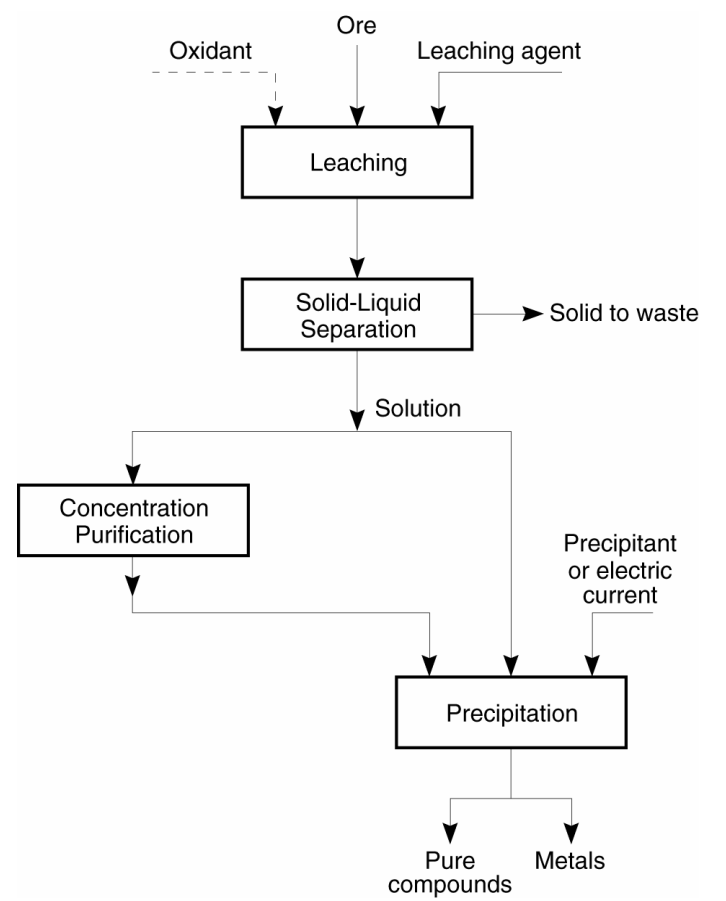

Figure 2. General outline of hydrometallurgical processes.

\section{Hydro-Versus Pyrometallurgy}

In the past fifty years, hydrometallurgy has been vigorously competing with thermal methods. Pyrometallurgy was most successful when high-grade massive sulfide ores were treated in a blast furnace, because such furnace has maximum heat economy being itself a heat exchanger: the cold charge descending from the top is preheated by the hot gases ascending in the furnace. Dust problems were also minimum because the ore was in form of large lumps. With the exhaustion of such raw material, metallurgists turned their attention towards the treatment of low-grade ores. This necessitated extensive grinding and flotation of the sulfides which resulted in a finely divided concentrates as raw material. These, naturally, could not be charged to a blast furnace because if charged, they would block the movement of the ascending gases-hence the birth of the fossil-fired horizontal reverberatory furnace. This was a turning point to the worst with respect to pollution of the environment, high energy consumption, and excessive dust formation.

The first success for hydrometallurgy was at the beginning of the twentieth century when a process for the production of alumina from bauxite was invented which rapidly displaced the existing pyrometallurgical method. Another success for hydrometallurgy was in the production of zinc when in 1980 a new process displaced the old pyromtallurgical process. At the beginning of the twenty first century a similar process was applied for treating copper concentrates thus demonstrating that the future is for hydrometallurgy and in particular pressure hydrometallurgy. The advantages of hydrometallurgy can be outlined as follows.

\subsection{Sulfur Dioxide Generation}

During the pyrometallurgical treatment of sulfide ores, if $\mathrm{SO}_{2}$ formed is in high enough concentration, it must be used for making acid and a nearby market for this acid must be found. Shipping sulfuric acid long distances is expensive and hazardous. If the $\mathrm{SO}_{2}$ concentration is too low for making acid, disposal methods must be found. These are available but expensive. As a result, in many cases $\mathrm{SO}_{2}$ is simply emitted to the atmosphere. On the other hand, sulfides can be treated by hydrometallurgical methods without generating $\mathrm{SO}_{2}$, hence the independence of sulfuric acid manufacture. Elemental sulfur produced by this rout can be easily stockpiled, or transported safely for long distances at low cost.

\subsection{Material Handling}

In pyrometallurgical processes, the metallurgist is forced to transfer molten slags and matte from one furnace to the other in large, heavy, refractory-lined ladles. Beside the inconvenience and the cost of handling these materials, there is also the inevitable gas emission from them because they are usually saturated with $\mathrm{SO}_{2}$ and during transfer they cool down a little resulting in decreased gas solubility hence the inconvenient working conditions. In hydrometallurgical plants, solutions and slurries are transferred by pipelines without any problem.

\subsection{Energy Consumption}

Because of the high temperatures involved in pyrometallurgical processes, which is usually around $1200^{\circ} \mathrm{C}$, the reaction rates are high but much fuel will be needed. To make a process economical, heat recovery systems are essential. Heat can be readily recovered from hot gases, but rarely from molten slag or molten metal. Thus, a great deal of energy is lost. Further, the equipments needed for heat economy are bulky and expensive. In hydrometallurgical processes, on the other hand, less fuel is needed because of the low temperatures involved (usually below $100^{\circ} \mathrm{C}$ ). Heat economy is usually no problem.

\subsection{Dust Formation}

Gases leaving furnaces carry over large amounts of fine dust. This must be recovered to abate pollution and because the dust itself is also a valuable material. The technology of dust recovery is well established but the equipment is bulky and expensive. In hydrometallurgical processes, this is no problem because wet material is usually handled. 


\subsection{Treatment of Complex Ores}

Treatment of complex ores by pyrometallurgical method is unsuitable because separation is difficult; this is, however suitable by hydrometallurgy.

\subsection{Treatment of Low-Grade Ores}

Treatment of low-grade ores by pyrometallurgy is unsuitable because of the large amount of energy required to melt the gangue minerals. On the other hand it is especially suitable by hydrometallurgy if a selective leaching agent is used.

\subsection{Economics}

The economics of a pyrometallurgical process is usually suitable for large scale operations and this requires a large capital investment. On the other hand, hydrometallurgical processes are suitable for small scale operations and therefore low capital investment.

\subsection{Waste Disposal}

Many waste products of pyrometallurgical processes are usually coarse and harmless. For example, slags, which are a silicate phase, can be stored in piles exposed to air and rain without the danger of dissolution and contaminating the streams. They are, however, unacceptable from the aesthetic point of view. On the other hand most residues of hydrometallurgical processes are finely divided solids. If they are dry, they may create dust problems when the wind blows and when wet they will gradually release metal ions in solution which may contaminate the environment. However, disposal of waste solution in hydrometallurgical operations is less troublesome than disposal of gases in pyrometallurgy. Even in a pyrometallurgical process water-scrubbing of a gas before disposal will eventually have a disposal problem with that water.

\section{Pressure Leaching}

Pressure leaching is a relatively recent technology that can be effectively applied for treating a variety of concentrates. A pressure leaching plant (Figure 3) is essentially composed of a high pressure pump (Figure 4) that continuously forces the concentrate or ore slurry into an autoclave (Figure 5) heated at a temperature of $150^{\circ} \mathrm{C}$ $200^{\circ} \mathrm{C}$ and operating at high pressure. The slurry leaving the autoclave is then introduced in flash tanks (Figure 6) where sudden expansion takes place thus releasing lowpressure steam that is used for pre-heating the feed slurry (Figure 7) and at the same time decreasing the pressure and temperature of the slurry to permit filtration at ambient conditions. In such system heat economy is maximum.

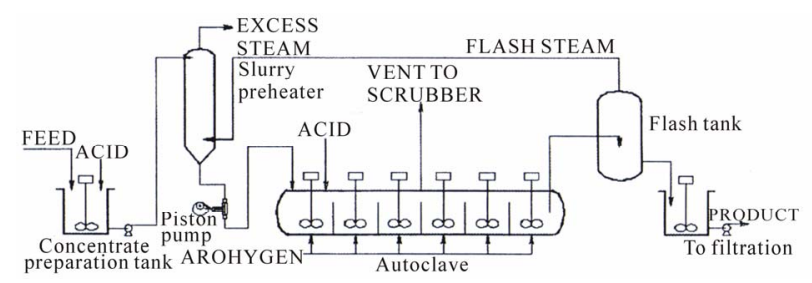

Figure 3. A pressure leaching plant [2].

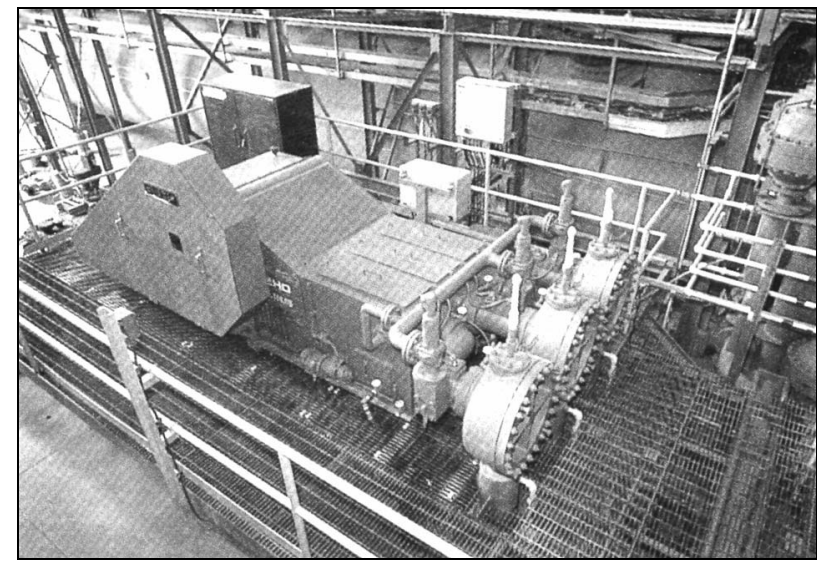

Figure 4. High pressure piston pump [2].

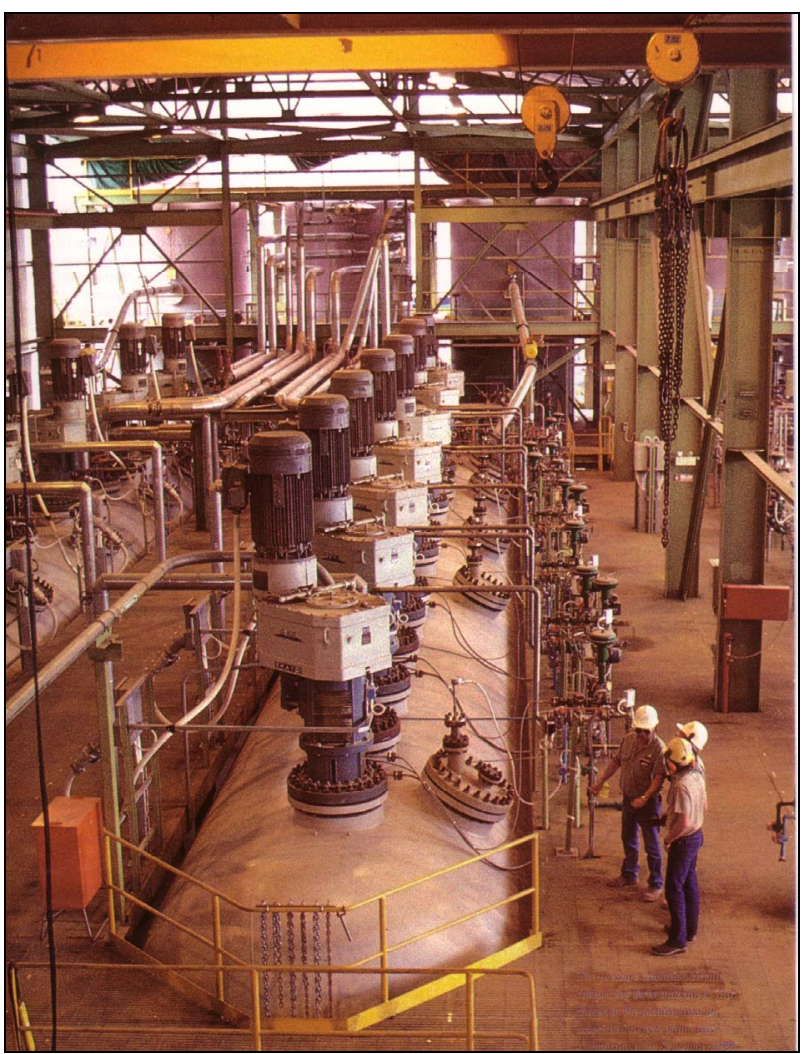

Figure 5. A typical autoclave [2].

\section{Abandoned but Not Forgotten}

In the early 1970 many hydrometallurgical processes for 


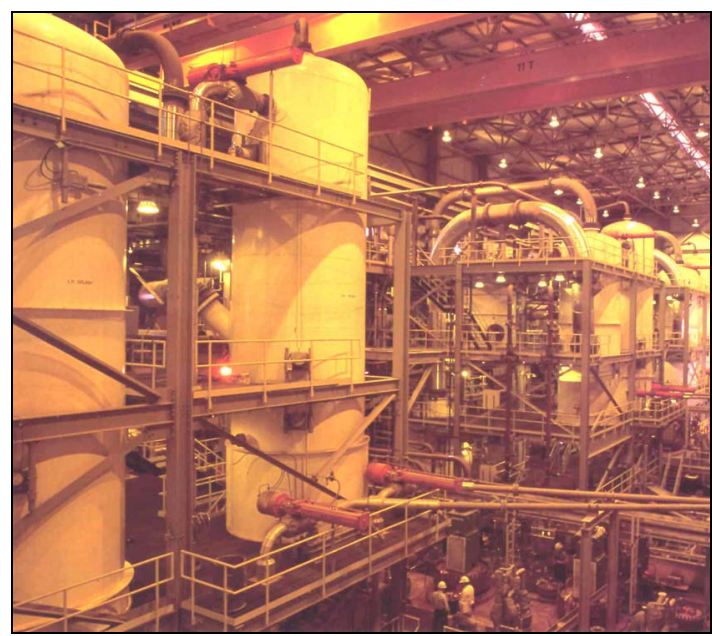

Figure 6. Flash tanks [2].

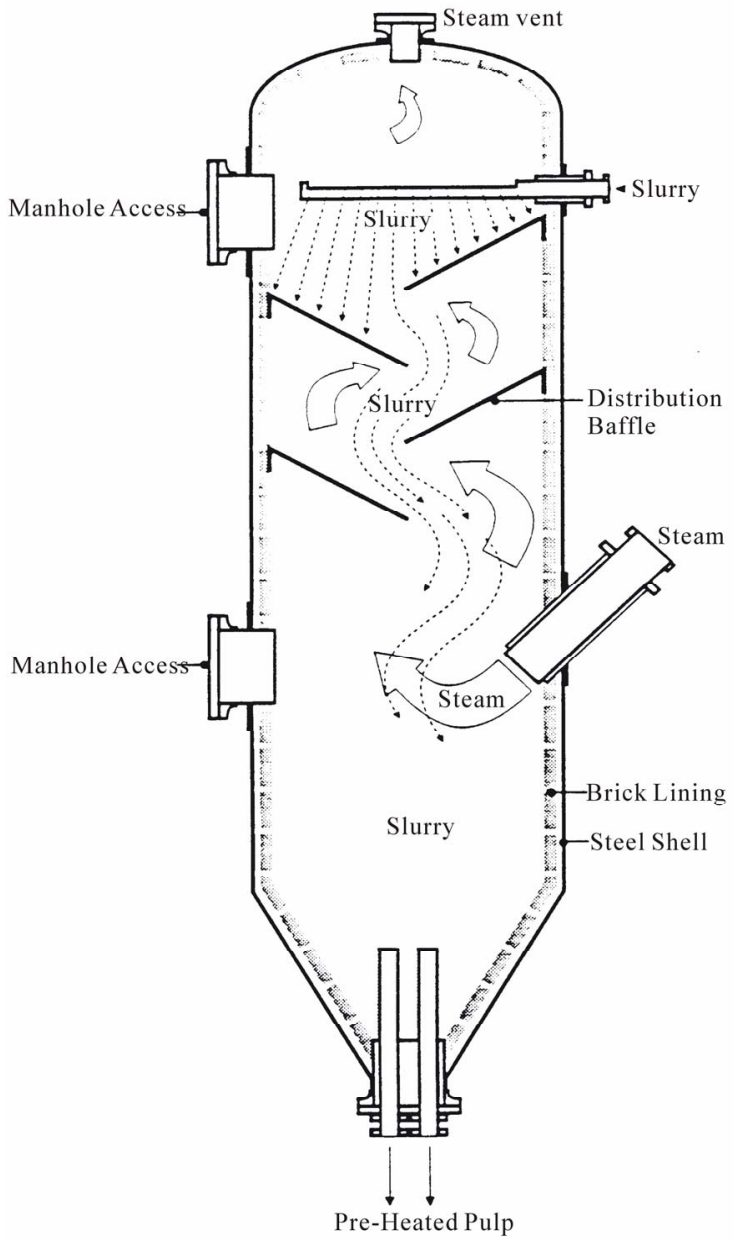

Figure 7. Slurry pre-heater [2]. copper production were developed but were abandoned few years later for various reasons. The situation how ever has changed and the industry is now mature enough [4].

\section{Conclusion}

In conclusion, the relatively new domain of hydrometallurgy and particularly pressure hydrometallurgy opens the way for many countries to exploit their mineral wealth without the need to rely on multinational companies to invest huge sums in building large smelters. Also, shipping concentrates is no longer a desired way to improve the economy of a country since local processing is now feasible using new technology. Investment in metallurgical education is essential.

\section{REFERENCES}

[1] F. Habashi, "Metals from Ores. An Introduction to Extractive Metallurgy,” Métallurgie Extractive Québec, Québec City, 2003. www.zone.ul.ca

[2] F. Habashi, “A Textbook of Hydrometallurgy,” 2nd Edition, Métallurgie Extractive Québec, Québec City, 1993, 1999. www.zone.ul.ca

[3] F. Habashi, "Handbook of Extractive Metallurgy," WILEY-VCH, Weinheim, 1997.

[4] F. Habashi, "Abandoned but Not Forgotten. The Recent History of Copper Hydrometallurgy," In: P. A. Riveras, et al., Eds., The John E. Dutrizac Symposium on Copper Hydrometallurgy, CIM, Montreal, 2007, pp. 3-19. 